\title{
PELAYANAN KB MELALUI PEMASANGAN IMPLAN DAN IUD DALAM RANGKA BAKTI SOSIAL KB-KES IBI PROVINSI RIAU DI STADION RUMBAI PEKANBARU
}

\author{
Miratu Megasari, SST, M.Kes ${ }^{(1)}$, Hetty Ismainar ${ }^{(2)}$ Yulrina Ardhiyanti $^{(3)}$ \\ Email : miratu090586@htp.ac.id
}

\begin{abstract}
ABSTRAK
Keluarga Berencana merupakan suatu program pemerintah yang dirancang untuk menyeimbangkan antara kebutuhan dan jumlah penduduk. Perencanaan jumlah keluarga dengan pembatasan bisa dilakukan dengan penggunaan alat kontrasepsi. Metode kontrasepsi yang diharapkan adalah yang dapat digunakan secara efektif oleh Pasangan Usia Subur (PUS) baik wanita atau istri maupun pria atau suami sebagai sarana pengendalian kelahiran. Metode Kontrasepsi Jangka Panjang (MKJP) adalah alat kontrsepsi yang digunakan untuk menunda, menjarangkan kehamilan, serta menghentikan kesuburan, yang digunakan jangka panjang, seperti : IUD, implan dan kontrasepsi mantap. Esensi tugas program Keluarga Berencana menurunkan Total Fertility Rate (TFR) agar dapat mengurangi beban pembangunan demi terwujudnya kebahagiaan dan kesejahteraan bagi rakyat dan bangsa Indonesia. Kegiatan bakti sosial IBI KB-Kesehatan merupakan langkah yang strategis untuk mencapai visi pemerintah provinsi Riau yang sehat dan sejahtera masyarakatnya. Bekerjasama dengan Ikatan Bidan Indonesia (IBI) dengan tujuan mempercepat pencapaian keluarga sejahtera melalui pelayanan kontrasepsi MKJP.
\end{abstract}

Keyword : Pelayanan KB, Pemasangan Implan dan IUD, KB-Kes IBI Provinsi Riau

Kata Kunci : Pelayanan KB, Pekanbaru 


\section{PENDAHULUAN}

Keluarga Berencana (KB) adalah usaha untuk mengontrol jumlah dan jarak kelahiran anak, untuk menghindari kehamilan yang bersifat sementara dengan menggunakan kontrasepsi sedangkan untuk menghindari kehamilan yang sifatnya menetap yang bisa dilakukan dengan cara sterilisasi. Keluarga Berencana merupakan suatu program pemerintah yang dirancang untuk menyeimbangkan antara kebutuhan dan jumlah penduduk. Perencanaan jumlah keluarga dengan pembatasan bisa dilakukan dengan penggunaan alat kontrasepsi (Dwijayanti, 2006).

Kontrasepsi adalah metode atau alat yang digunakan untuk mencegah kehamilan. Berbagai metode kontrasepsi tersedia untuk Pasangan Usia Subur (PUS) dari yang metode sederhana sampai metode modern. Alat kontrasepsi yang banyak digunakan oleh masyarakat saat ini, seperti : kondom pria / wanita, pil $\mathrm{KB}$, suntikan $\mathrm{KB}$, IUD (Intra Uterine Device), Implan, serta sterilisasi yaitu : Tubektomi dan Vasektomi.

Metode kontrasepsi yang diharapkan adalah yang dapat digunakan secara efektif oleh Pasangan Usia Subur (PUS) baik wanita atau istri maupun pria atau suami sebagai sarana pengendalian kelahiran. Idealnya, penggunaan alat kontrasepsi terlebih bagi pasutri (pasangan suami istri) merupakan tanggung jawab bersama antara pria dan wanita, sehingga metode yang dipilih mencerminkan kebutuhan serta keinginan suami istri tanpa mengesampingkan hak reproduksi masing-masing (Hartanto, 2010).

Metode Kontrasepsi Jangka Panjang (MKJP) adalah alat kontrsepsi yang digunakan untuk menunda, menjarangkan kehamilan, serta menghentikan kesuburan, yang digunakan jangka panjang, seperti : IUD, implan dan kontrasepsi mantap. Indonesia merupakan negara dengan jumlah penduduk berada pada posisi keempat di dunia, dengan laju pertumbuhan yang masih relatif tinggi. Esensi tugas program Keluarga Berencana menurunkan Total Fertility Rate (TFR) agar dapat mengurangi beban pembangunan demi terwujudnya kebahagiaan dan kesejahteraan bagi rakyat dan bangsa Indonesia.

Pemakaian MKJP memiliki banyak keuntungan dari segi program maupun dari sisi klien (pemakai). Selain mempercepat penurunan TFR, penggunaan kontrsepsi MKJP juga lebih efisien karena dapat dipakai dalam waktu 
yang lama serta lebih aman dan efektif. Metode kontrsepsi ini sangat tepat digunakan pada kondisi krisis yang dialami oleh sebagian besar masyarakat Indonesia terutama pada masyarakat yang tergolong kurang mampu / miskin. Dalam situasi ini, kelompok masyarakat miskin merupakan fokus garapan pemerintah yang dianggap sangat strategis (Prawiro, 2012).

Kegiatan bakti sosial IBI KBKesehatan merupakan langkah yang strategis untuk mencapai visi pemerintah provinsi Riau yang sehat dan sejahtera masyarakatnya. Bekerjasama dengan Ikatan Bidan Indonesia (IBI) dengan tujuan mempercepat pencapaian keluarga sejahtera melalui pelayanan kontrasepsi MKJP. Oleh karena itu dirasa perlu untuk dilakukan pengabdian masyarakat dengan tema : "Pelayanan KB Melalui Pemasangan Implan dan IUD dalam Rangka Bakti Sosial KB-Kes IBI Provinsi Riau Di Stadion Rumbai Pekanbaru".

\section{METODE KEGIATAN}

Metode pengabdian kepada masyarakat yang dilaksanakan sebagai berikut :

1. Pemasangan Implan dan IUD

Pemasangan Implan dan IUD dilakukan di Stadion Kaharuddin Nasution, Rumbai, Pekanbaru dengan menggunakan ruangan dan mobil ambulance. Pemasangan implan dilakukan di satu ruangan yang dibagi menjadi beberapa bilik dengan bed tempat tidur pasien. Sedangkan pemasangan IUD dilakukan di dalam mobil ambulance untuk lebih menjaga privasi dan kenyamanan pasien. Pemasangan implan dan IUD dilakukan oleh bidan yang telah memiliki sertifikat pelatihan CTU (Contraception Technology Update).

2. Evaluasi

Pasien yang telah dipasang implan dan IUD diberikan terapi dan konseling post pemasangan. Tujuannya agar kontrasepsi yang digunakan efektif dan pasien memahami kemungkinan efek samping yang nantinya dialami.

\section{HASIL DAN PEMBAHASAN}

\section{Hasil Pelaksanaan}

Kegiatan Bakti Sosial IBI KB-Kes Provinsi Riau telah dilaksanakan pada tanggal 11 April 2017 di Stadion Kaharuddin Nasution, Rumbai, Pekanbaru dengan tema : "Bidan mengenal kesehatan keluarga dengan layanan holistik dan berkesinambungan". Pelayanan KB diberikan gratis kepada masyarakat. Tujuan diadakannya kegiatan ini adalah meningkatkan KB 
untuk membantu masyarakat menurunkan angka kematian ibu dan anak serta angka kesakitan.

Kegiatan yang dilakukan meliputi :

1. Pelayanan KB gratis.

2. Test IVA sebagai skrining Kanker Serviks.

3. Kegiatan donor darah.

4. Pemeriksaan kolesterol dan gula darah.

5. Pemeriksaan HIV/AIDS.

Sasaran pelayanan KB dengan MKJP yaitu :

1. Pemasangan IUD sebanyak 3.145 orang.

2. Pemasangan implan sebanyak 6.600 orang.

3. Medis Operatif Wanita (MOW) sebanyak 570 orang.

Medis Operatif Pria (MOP) sebanyak 120 orang.

\section{PEMBAHASAN}

Kegiatan Bakti Sosial IBI KB-

Kes Provinsi Riau yang telah dilaksanakan pada tanggal 11 April 2017 di Stadion Kaharuddin Nasution, Rumbai, Pekanbaru disambut antusias oleh ratusan masyarakat. Gubernur Riau Arsyadjuliandi Rachman mengatakan, tenaga bidan yang tergabung dalam Ikatan Bidan Indonesia (IBI) menjadi ujung tombak dalam mensosialisasikan program Keluarga Berencana (KB). Keberhasilan program KB yang sudah dimulai sejak era Presiden Soeharto, pelaksanaannya di masyarakat sangat ditentukan oleh para bidan.

Pertumbuhan penduduk di Riau cukup tinggi sekitar 3,59 persen. Namun angka itu menjadi tinggi karena persoalan perpindahan penduduk. Riau menjadi sasaran transmigrasi atau perpindahan dari daerah provinsi tetangga akibat banyaknya industri makro di Riau. Pertumbuhan penduduk akan menjadi masalah besar untuk ke depannya tidak hanya di Riau namun di Indonesia dan dunia. Bumi yang sebenarnya hanya mampu menampung 3-4 miliar manusia, kini bahkan sudah dihuni oleh hampir 8 miliar manusia. Krisis pangan dan energi akan terjadi. Itu sebabnya, program KB harus menjadi komitmen semua pihak.

\section{KESIMPULAN}

Dari kegiatan pengabdian masyarakat ini dapat disimpulkan bahwa :

1. Jumlah WUS yang menggunakan MKJP mencapai target sasaran.

2. Kegiatan pelayanan $\mathrm{KB}$ melalui $\mathrm{KB}-$ Kes oleh IBI dan BKKBN berjalan sesuai dengan rencana . 
DAFTAR PUSTAKA

Anggraini. (2012). Pelayanan Keluarga

Berencana. Yogyakarta : Rohim.

BKKBN. (2001). Pedoman Kebijakan

Teknis Keluarga Berencana dan Kesehatan Reproduksi. Jakarta : BKKBN.

BKKBN. (2008). Rapat Kerja Program

KB Nasional Jawa Tengah Tahun 2008 : Kebijakan dan Strategi Operasional Pencapaian Sasaran Tahun 2008-2009. Jawa Tengah.

Dwijayanti, R. (2006). Analisis Respon Masyarakat Desa terhadap Program KB dalam Rangka Peningkatan Kualitas Sumber Daya Manusia di Desa Cihideung Udik Kab. Bogor, (Online),

(http://dikti.go.id/pkm/pkmi-award2006/pdf/pkmi06-016.pdf, diakses 20 April 2017).

Hartanto, H. (2010). Keluarga Berencana dan Kontrasepsi. Jakarta : Pustaka Sinar Harapan.
Meilani. (2010). Pelayanan Keluarga Berencana. Yogyakarta : Fitramaya. Proverawati, A., Islaely, A.D \& Aspuah,S. (2010). Panduan Memilih Kontrasepsi. Yogyakarta : Nuha Medika.

UU RI Nomor 10 Tahun 1992 tentang Perkembangan Kependudukan dan Pembangunan Keluarga Sejahtera, (Online),

(http://birohukumsiskum.sumutprov. go.id/myadmin/undang/10\%20Tahun \%201992.pdf, diakses 20 April 2017).

Pendit. (2007). Pelayanan Keluarga Berencana. Yogyakarta : Pustaka Rihana.

Setiyaningrum, E., \& Aziz, Z.B. (2014). Pelayanan Keluarga Berencana dan Kesehatan Reproduksi. Jakarta : Trans Info Media.

Sulistyawati, A. Pelayanan Keluarga Berencana. Jakarta : Salemba Medika. 